\title{
Fluorite-Type Solid Solutions in the System Y-Ta-O-N: A Nitrogen-Rich Analogue to Yttria-Stabilized Zirconia (YSZ)
}

\author{
H. Schilling ${ }^{\mathrm{a}}$, H. Wolff ${ }^{\mathrm{b}}$, R. Dronskowski ${ }^{\mathrm{b}}$, and M. Lerch ${ }^{\mathrm{a}}$ \\ ${ }^{a}$ Institut für Chemie, TU Berlin, Straße des 17. Juni 135, D-10623 Berlin \\ ${ }^{\mathrm{b}}$ Institut für Anorganische Chemie, RWTH Aachen, Landoldtweg 1, D-52056 Aachen \\ Reprint requests to Prof. Dr. M. Lerch. E-mail: Lerch@chem.tu-berlin.de
}

Z. Naturforsch. 61b, 660-664 (2006); received November 11, 2005

Dedicated to Professor Wolfgang Jeitschko on the occasion of his $70^{\text {th }}$ birthday

Fluorite-type phases in the system Y-Ta-O-N have been prepared by ammonolysis of Y-Ta-O precursors. X-ray powder patterns show unusual asymmetrical reflection profiles explained by DFT and MD methods. The anion vacancy concentration of some of these oxynitrides is similar to that of yttria-doped zirconia, commercially used as solid electrolyte in fuel cells. Hence, these compounds are interesting candidates for mixed oxygen-nitrogen superion conductors.

Key words: Tantalum Oxynitride, Fluorite-Type Structure, Synthesis, Computational Chemistry

\section{Introduction}

Oxygen superionic conductors based on yttriastabilized zirconia (YSZ) have become important materials for applications as electrolytes in solid oxide fuel cells (SOFC) and oxygen sensors [1]. Undoped $\mathrm{ZrO}_{2}$ (baddeleyite) has a monoclinic structure closely related to the fluorite-type with cations coordinated by seven anions. It undergoes phase transitions to a tetragonally distorted fluorite-type structure $\left(T>1170{ }^{\circ} \mathrm{C}\right)$ and, at higher temperatures, to the aristotype cubic fluorite structure $\left(T>2370{ }^{\circ} \mathrm{C}\right)$. Tetragonal and cubic phases can be stabilized to exist at $r$.t. by doping with aliovalent oxides $\left(\mathrm{MgO}, \mathrm{CaO}, \mathrm{Sc}_{2} \mathrm{O}_{3}, \mathrm{Y}_{2} \mathrm{O}_{3}\right)$, the first known example being the Nernst mass (a solid solution of $8 \% \mathrm{Y}_{2} \mathrm{O}_{3}$ in $\mathrm{ZrO}_{2}$ ) [2]. Anion vacancies are formed due to the lower charge of the dopant cations. An alternative way to create anion vacancies is the substitution of oxygen by nitrogen which can be described by the following equation using the Kröger-Vink-notation $\left(\mathrm{O}_{\mathrm{O}}{ }^{\mathrm{x}}: \mathrm{O}^{2-}\right.$-ion on oxygen site, $\mathrm{N}_{\mathrm{O}}{ }^{\prime}: \mathrm{N}^{3-}$-ion on regular oxygen site, $\mathrm{V}_{\mathrm{O}}{ }^{\circ}$ : vacancy in the anion substructure):

$$
3 \mathrm{O}_{\mathrm{O}}{ }^{\mathrm{x}}+\mathrm{N}_{2}=2 \mathrm{~N}_{\mathrm{O}}{ }^{\prime}+\mathrm{V}_{\mathrm{O}}^{\circ \circ}+3 / 2 \mathrm{O}_{2}
$$

Nitrogen can be incorporated into $\mathrm{ZrO}_{2}$ by direct nitridation in a nitrogen atmosphere at temperatures above $1400{ }^{\circ} \mathrm{C}$ [3]. Cation- and anion-doping are stabilizing the high-temperature phases in an additive way $[4,5]$. Single-phase cubic fluorite-type oxynitrides

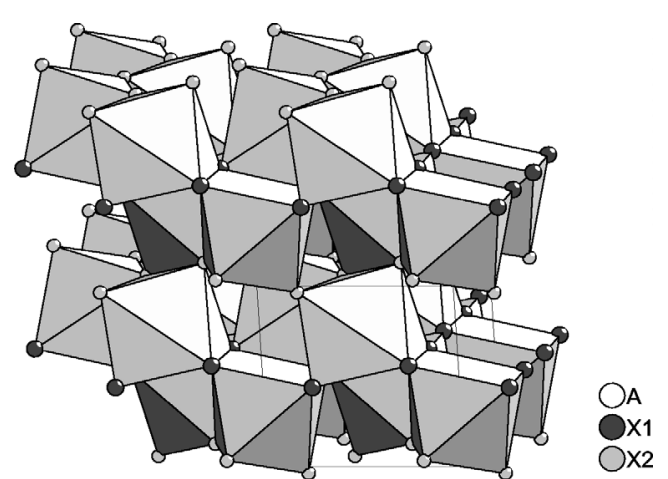

Fig. 1. Baddeleyite structure $\left(\mathrm{ZrO}_{2}: \mathrm{X} 1=\mathrm{X} 2=\mathrm{O}\right.$ and $\mathrm{TaON}$ : $\mathrm{X} 1=\mathrm{N}, \mathrm{X} 2=\mathrm{O})$.

are obtained with significantly lower dopant cation concentrations compared to pure oxide-doped zirconia.

The main objective of our research is to prepare anion-conducting materials with a (favorably high) nitrogen content and to study their structural and physical properties especially with regard to the behavior of nitride $\left(\mathrm{N}^{3-}\right)$ ions. Because the maximum amount of nitrogen in zirconia-based fluorite-type phases is limited to about $20 \%$ of the anions, a new compound, TaON, was chosen, which is isotypic to $\mathrm{ZrO}_{2}$ [6]. The anion distribution was determined by neutron diffraction studies and is discussed in detail in [7]. In TaON, oxygen and nitrogen are ordered on two different crystallographic sites. Oxide ions are located on sites coordinated by three cations, and nitride ions are sur- 
rounded by four cations (Fig. 1). Transitions to tetragonal or cubic high-temperature phases cannot be observed due to thermal decomposition above $\approx 1000{ }^{\circ} \mathrm{C}$. TaON can be prepared most easily by the treatment of $\mathrm{Ta}_{2} \mathrm{O}_{5}$ at about $900{ }^{\circ} \mathrm{C}$ for $c a .16 \mathrm{~h}$ with flowing ammonia gas bubbled through saturated ammonia solution at a flow rate of about $20 \mathrm{l} / \mathrm{h}$ [8].

The aim of the present work is to prepare and characterize tetragonal or cubic fluorite-type phases of TaON stabilized by doping with $\mathrm{Y}_{2} \mathrm{O}_{3}$. The formation of pyrochlore- and fluorite- type phases from oxides $R E \mathrm{TaO}_{4}(R E=\mathrm{Nd} \ldots \mathrm{Yb}, \mathrm{Y})$ under thermal ammonolysis conditions has been reported by Marchand and co-workers $[9,10]$. In order to obtain phases with high nitrogen content the dopant concentration $(R E=\mathrm{Y}$ in this work) had to be kept low. Samples in the composition range between 0 and 50 cation $\% \mathrm{Y}$ were prepared.

In order to augment the experimental studies, computational chemistry was called on for a better understanding of the structural properties as deduced from the experimentally observed diffraction data. Densityfunctional theory (DFT) appeared to be a fine instrument for investigations on doped $\mathrm{TaON}$, for it was successfully utilized in former studies on the pure TaON phase [11-13]. In addition, molecular dynamics (MD) simulations were carried out on structures which had been optimized using quantum-mechanical schemes.

\section{Experimental Section}

Synthesis

Amorphous ternary phases in the system Y-Ta-O were prepared using a modified Peccini method [14]. Tantalum chloride (Alfa Aesar, 99.99\%) was dissolved in ethanol containing citric acid in an excess of 12 times the $\mathrm{TaCl}_{5}$. Any dispersed $\mathrm{Ta}_{2} \mathrm{O}_{5}$ was removed by centrifugation. The resulting tantalum citrate complexes are insensitive to water. A stock solution with a defined content of tantalum citrate was obtained. Yttrium oxide (Alfa Aesar, 99.99\%) was dissolved upon heating in a small volume of hydrochloric acid. This $\mathrm{YCl}_{3}$ solution was poured into ethanol containing citric acid in an excess of 12 times the $\mathrm{YCl}_{3}$. Appropriate quantities of the two citrate solutions were mixed together and ethylene glycol in an excess of 17 times the metals content was added. The solvent and $\mathrm{HCl}$ were evaporated and the citrate complexes together with ethylene glycol were polymerized at about $150{ }^{\circ} \mathrm{C}$. The organic components of the polymer were burnt off at $600{ }^{\circ} \mathrm{C}$ for $16 \mathrm{~h}$ to give white amorphous powders. The chemical composition with respect to the cations was proved by EDX analysis. These oxides have been treated with ammonia gas at temperatures between 700 and $1000{ }^{\circ} \mathrm{C}$ for $16 \mathrm{~h}$ with a flow rate of $20 \mathrm{l} / \mathrm{h}$.

\section{N/O Analysis}

Nitrogen and oxygen contents were determined using a LECO TC-300 / EF-300 N/O analyzer (hot gas extraction). $\mathrm{Ta}_{2} \mathrm{O}_{5}$ and $\mathrm{Si}_{3} \mathrm{~N}_{4}$ were used as standard materials for calibration. The accuracy is about $2 \%$ of the N/O present.

\section{$X R D$}

A Siemens D5000 powder diffractometer $\left(\mathrm{Cu}-\mathrm{K}_{\alpha 1}\right.$ radiation, $\lambda=154.06 \mathrm{pm}$, position-sensitive detector) was used for XRD measurements at r.t., and a STOE STADI-P powder diffractometer (Mo- $\mathrm{K}_{\alpha 1}$ radiation, $\lambda=70.93 \mathrm{pm}$, imaging plate detector) with a graphite-heated resistance furnace was used for temperature-dependent measurements (samples in $\mathrm{SiO}_{2}$-glass capillaries under argon). Quantitative phase analysis and lattice parameter determination were performed by the program POWDER CELL 2.4. For Rietveld refinements the program package FULLPROF 2000 [15] was used. The profiles were fitted with a pseudo-Voigt function. The simulated patterns were generated with the program ATOMS 6.2 on the basis of the crystal coordinates obtained from the MD simulations employing extremely large unit cells without any symmetry restrictions (space group $P 1$ ).

\section{Total-energy calculations}

Total-energy calculations were carried out with the density-functional Vienna $A b$ initio Simulation Package (VASP) [16, 17] using Vanderbilt-type pseudopotentials [18] and a plane-wave basis set with a kinetic energy cutoff of $490 \mathrm{eV}$. Correlation and exchange terms of the electrons were taken into account by using the generalized gradient approximation (GGA) of Perdew and Wang [19]. The Brillouin zone integrations were performed at 128 irreducible $k$-points as they resolve from a $4 \times 8 \times 8$ Monkhorst-Pack grid [20] and at 16 irreducible $k$-points from a $4 \times 4 \times 4$ mesh for supercell calculations, respectively.

\section{Molecular dynamics simulations}

Molecular dynamics (MD) simulations were performed with the program aixCCAD [21,22] on the basis of the bond-length-bond-strength relationship using the parameters of Brese and O'Keeffe [23]. Simulations were executed over a total of 200000 steps of $0.001 \mathrm{fs}$ for boxes consisting of a microcanonical ensemble of close to 1000 atoms, applying a temperature of $300 \mathrm{~K}$.

\section{Results and Discussion}

Quantitative phase analyses have shown a decreasing amount of red-brown $\mathrm{Ta}_{3} \mathrm{~N}_{5}$ (which is obtained as single-phase from pure $\mathrm{Ta}_{2} \mathrm{O}_{5}$ under these conditions 


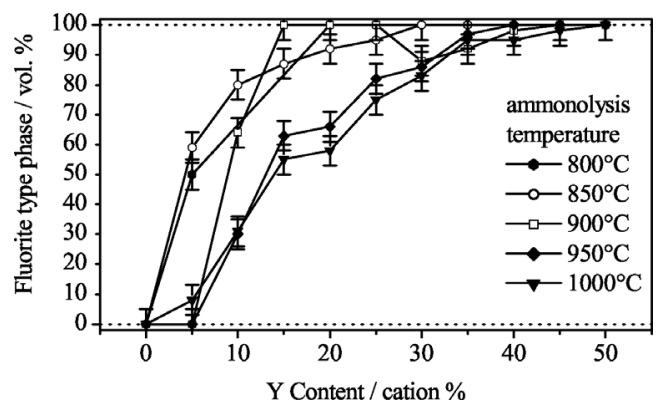

Fig. 2. Quantitative phase analysis of samples in the system Y-Ta-O-N.

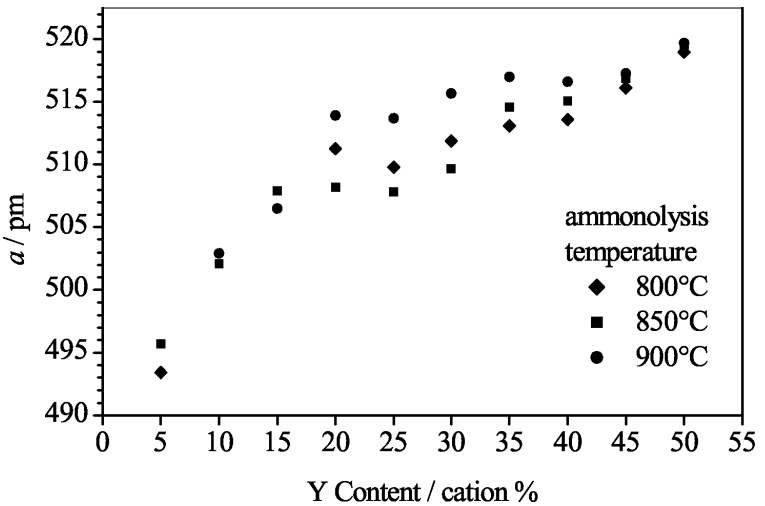

Fig. 3. Lattice parameters of the prepared fluorite-type phases. The given Y-content refers to the bulk sample.

of synthesis) with increasing dopant concentration. An increasing fraction of fluorite-type phase is formed instead (Fig. 2). Single-phase fluorite-type samples (brown) were obtained at a minimum Y-content of 15 cation-\%. At temperatures below $800{ }^{\circ} \mathrm{C}$ the specimens remain amorphous. Temperatures above $900{ }^{\circ} \mathrm{C}$ lead to the formation of black powders containing various amounts of $\mathrm{Ta}_{4} \mathrm{~N}_{5}, \mathrm{Ta}_{5} \mathrm{~N}_{6}$, and TaN, respectively.

The lattice parameter $a$ (Fig. 3) varies from ca. $495 \mathrm{pm}$ (5 cation \%-Y) to ca. 520 pm (50 cation- $\% \mathrm{Y})$. The parameter of single-phase $\mathrm{Y}_{0.15}$ $\mathrm{Ta}_{0.85} \mathrm{O}_{0.62} \mathrm{~N}_{1.15}(508.55(2) \mathrm{pm}$, Table 1), determined from the XRD pattern presented in Fig. 4, is nearly the same as for YSZ (e.g., $\mathrm{Y}_{0.16} \mathrm{Zr}_{0.84} \mathrm{O}_{1.92}$, 514.086(8) pm [24]). It should be mentioned that the reflection profiles are broad for all observed phases. Consequently, a slight structural distortion of the fluorite-type phases cannot be excluded on the basis of the diffraction data. In addition, the X-ray data do not allow the refinement of a possible ordering of the anions. No indications were found for vacancy ordering as known from the Sc-Ta-O-N system [25].
Table 1. Structural data of $\mathrm{Y}_{0.15} \mathrm{Ta}_{0.85} \mathrm{O}_{0.62} \mathrm{~N}_{1.15}$ from X-ray powder diffraction.

\begin{tabular}{ll}
\hline Structure type & fluorite \\
Space group & $F m \overline{3} m$ \\
Lattice parameters & $a=508.55(2) \mathrm{pm}$ \\
Unit cell volume & $V=131.52 \cdot 10^{6} \mathrm{pm}^{3}$ \\
Formula units & $Z=4$ \\
Calculated density & $\rho=9.74 \mathrm{~g} / \mathrm{cm}^{3}$ \\
Number of profile points & 4522 \\
$2 \theta$ Range & $10-95^{\circ}$ \\
Number of refined parameters & 17 \\
$R_{\mathrm{wp}}$ & 0.047 \\
$R_{\mathrm{Bragg}}$ & 0.025 \\
$R_{\exp }$ & 0.015 \\
$\mathrm{~S}$ & 3.1 \\
\hline
\end{tabular}

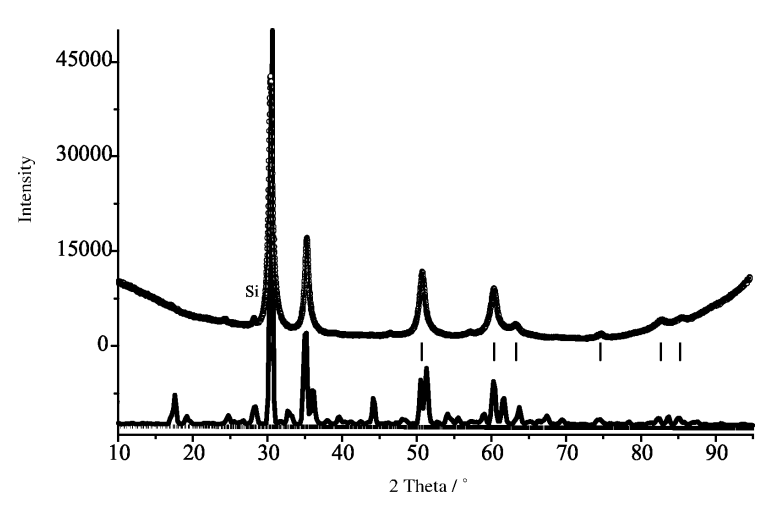

Fig. 4. X-ray powder pattern of $\mathrm{Y}_{0.15} \mathrm{Ta}_{0.85} \mathrm{O}_{0.62} \mathrm{~N}_{1.15}$ with results of the Rietveld refinement (a) and simulated $\mathrm{X}$-ray powder pattern of $\mathrm{Y}_{0,125} \mathrm{Ta}_{0,875} \mathrm{O}_{0,875} \mathrm{~N}$ (b) on the basis of total-energy and molecular-dynamics calculations.

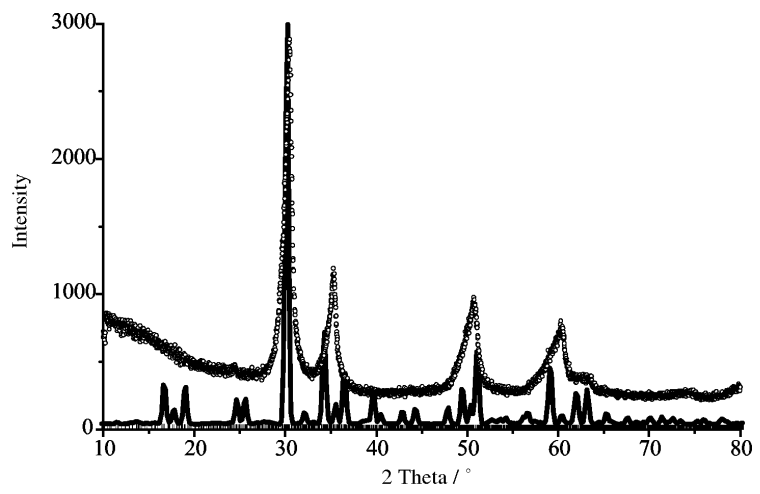

Fig. 5. X-ray powder pattern of $\mathrm{Y}_{0.30} \mathrm{Ta}_{0.70} \mathrm{O}_{1.30} \mathrm{~N}_{0.59}$ (a) and simulated X-Ray powder pattern of $\mathrm{Y}_{0.375} \mathrm{Ta}_{0.625}$ $\mathrm{O}_{0,625} \mathrm{~N}$ (b); see also Fig. 4.

As already mentioned, it is remarkable that most samples show unusual asymmetric reflection profiles, as given in the upper parts of Fig. 4 and, especially, of Fig. 5, and it is most interesting to ask where that asymmetry may arise from. We first recall that the width of 
all Bragg reflections is a simple function of the crystallites' size whereas profile asymmetries are usually included by assuming a (macroscopic) "strain" between the diffracting grains such that the "strain" serves as a simple fit parameter needed to retain the smallest possible unit cell in the crystallographic description. We now take an alternative point of view and propose that the asymmetry is an intrinsic phenomenon of the material, making macroscopic "strains" unnecessary for fitting the data. As anticipated, quantum-chemical totalenergy calculations confirm triclinic distortions of the fluorite-type minimum unit cells in all cases, somewhat depending on the individual compositions. Given that any macroscopic probe may be looked upon as an ensemble of a vast collection of individually distorted "unit cells", the statistically distributed structural distortions will make the material still appear as cubic but with an asymmetric reflection profile. In other words, the crystallographic unit cell appears as an oversimplification, and the residual error (= asymmetric profile) then demands an empirical strain parameter.

This is also what is found on the basis of moleculardynamics type calculations using very large supercells containing a total of almost 1000 atoms. For the latter, the (questionable) crystallographic assumption (minimum-size unit cell and highest possible symmetry) is abandoned, but the triclinic supercells' theoretical diffraction diagrams clearly appear as cubic (Fig. 4 and 5, lower parts) in the first place and also exhibit asymmetric reflection profiles throughout - without any empirical strain! Nonetheless, even this extended description appears as too small since a few simulated reflections at low $2 \theta$ values cannot be observed experimentally; that is, the symmetry of the computational model is too high due to the periodic boundary conditions. In addition, the question of whether or not weak peaks may be observed at all is a function of the reflections' width and the overall background noise.

The results of N/O analyses are depicted in Fig. 6. No systematic dependence of the nitrogen content on the reaction temperature can be observed. Cation:anion ratios from $1: 2$ to $1: 1.5$ are marked by dotted lines in the diagram. Fluorite-type phases without anion vacancies are represented by a symbol on the $1: 2$ line. Samples at Y-contents above $c a$. 15 cation-\% typically have cation to anion ratios from $1: 1.8$ to $1: 1.9$. These results clearly show that anion vacancies are present in the obtained fluorite-type phases. From

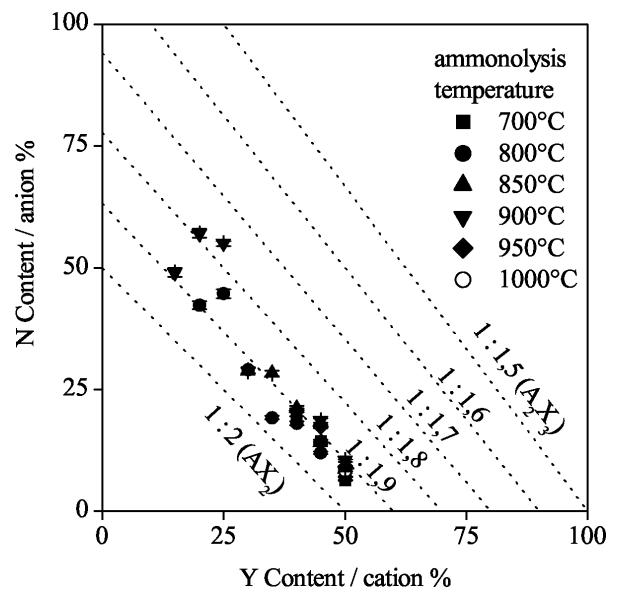

Fig. 6. Analytical results of prepared single-phase fluoritetype samples.

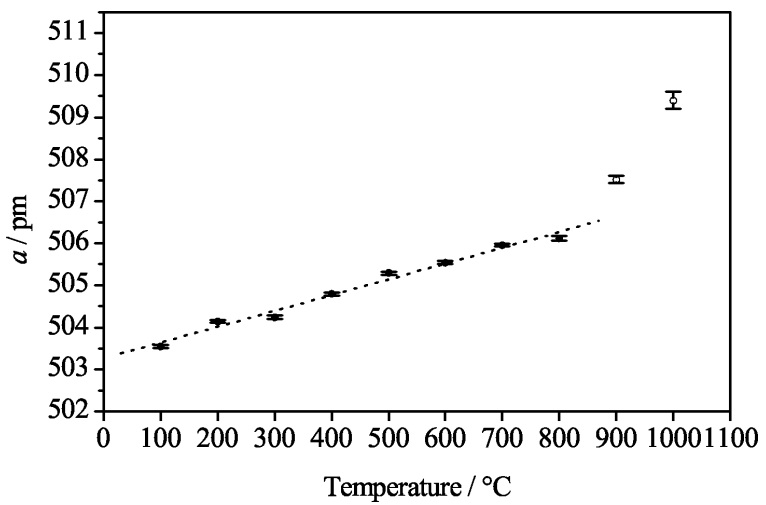

Fig. 7. Thermal expansion of $\mathrm{Y}_{0.15} \mathrm{Ta}_{0.85} \mathrm{O}_{0.62} \mathrm{~N}_{1.15}$. Decomposition begins at about $800^{\circ} \mathrm{C}$.

yttria-doped zirconia it is known that phases with ratios around 1:1.9 have the best ionic conductivity. Therefore, Y-Ta-O-N materials with such vacancy concentrations are promising candidates for mixed oxygen/nitrogen ion conductivity. Yttria-doped zirconium oxynitrides show remarkable ionic conductivity [5] and high nitrogen mobility [26].

Thinking about using tantalum oxynitrides as solid electrolytes, thermal expansion and stability are important factors. In air, all these oxynitrides react with oxygen to give oxides at temperatures above $500{ }^{\circ} \mathrm{C}$. The thermal expansion of a selected specimen in inert atmosphere was investigated using in situ high-temperature X-ray diffraction (Fig. 7). For $\mathrm{Y}_{0.15} \mathrm{Ta}_{0.85} \mathrm{O}_{0.62} \mathrm{~N}_{1.15}$, the volume thermal expansion coefficient in the temperature range between 100 and $800{ }^{\circ} \mathrm{C}$ is $\gamma=2.07 \cdot 10^{-5} \mathrm{~K}^{-1}$. For comparison, YSZ $\left(\mathrm{Y}_{0.15} \mathrm{Zr}_{0.85} \mathrm{O}_{1.93}\right)$ shows a larger thermal expan- 
sion, namely $\gamma=3.3 \cdot 10^{-5} \mathrm{~K}^{-1}$ [27]. Consistent with this result, a lower thermal expansion coefficient of the oxynitride relative to the oxide is also found for the undoped compounds: $\mathrm{TaON}\left(\gamma=3.9 \cdot 10^{-5} \mathrm{~K}^{-1}\right)$, $\mathrm{ZrO}_{2}\left(\gamma=5.1 \cdot 10^{-5} \mathrm{~K}^{-1}\right)$ [28]. Thermal decomposition in argon atmosphere begins at temperatures higher than $800^{\circ} \mathrm{C}$. This leads to serious problems in sintering pressed pellets to ceramics with a high density important for the investigation of the ionic conductivity by impedance spectroscopy. Unfortunately, ammonolysis of sintered Y-Ta-O pellets or even crystalline powders leads to the formation of multi-phase samples containing also ternary oxide phases. Respecting these facts, the most promising route to dense materials is the pulsed laser deposition (PLD), allowing the preparation of dense oxynitride films. With the knowledge of compositions leading to single-phase fluorite phases this will be done in the near future [29].

\section{Acknowledgement}

This work is supported by the DFG within the priority program 1136.
[1] P. Knauth, H.L. Tuller, J. Am. Ceram. Soc. 85, 1654 (2002).

[2] W. Nernst, U.S. Pat. No. 685730 (1901).

[3] Y. B. Cheng, D. P. Thompson, Special Ceram. 9, 149 (1992).

[4] M. Lerch, J. Lerch, R. Hock, J. Wrba, J. Solid State Chem. 128, 282 (1997).

[5] J. Wendel, M. Lerch, W. Laqua, J. Solid State Chem. 142, 163 (1999).

[6] M. Weishaupt, J. Strähle, Z. Anorg. Allg. Chem. 429, 261 (1977)

[7] D. Armytage, B.E. F. Fender, Acta Crystallogr. B30, 809 (1974).

[8] S. J. Clarke, K. A. Hardstone, C. W. Michie, M. J. Rosseinsky, Chem. Mater. 14, 2664 (2002).

[9] F. Pors, R. Marchand, Y. Laurent, J. Solid State Chem. 107(1), 39 (1993).

[10] P. Maillard, F. Tessier, E. Orhan, F. Cheviré, R. Marchand, Chem. Mater. 17, 152 (2005).

[11] C. M. Fang, E. Orhan, G. A. de Wijs, H. T. Hintzen, R. A. de Groot, R. Marchand, J.-Y. Saillard, G. de With, J. Mater. Chem. 11, 1248 (2001).

[12] C. M. Fang, R. Metselaar, H. T. Hintzen, G. de With, Key Eng. Mater. 206-213, 1149 (2002).

[13] M.-W. Lumey, R. Dronskowski, Z. Anorg. Allg. Chem. 623, 2173 (2003).

[14] T. Okubo, M. Kakihana, J. Alloys Compd. 256, 151 (1997).

[15] J. Rodriguez-Carvajal, Abstracts of the Satellite Meeting on Powder Diffraction of the XV Congress of the IUCr, 127 (1990).
[16] G. Kresse, J. Furthmüller, Comp. Mater. Sci. 6, 15 (1996).

[17] G. Kresse, J. Furthmüller, Phys. Rev. B54, 11169 (1996).

[18] D. Vanderbilt, Phys. Rev. B41, 7892 (1990).

[19] J.P. Perdew, in: P. Ziesche, H. Eschrig (eds.): Electronic Structure of Solids '91, p. 11, Akademie Verlag, Berlin (1991).

[20] H. J. Monkhorst, J. D. Pack, Phys. Rev. B13, 5188 (1976).

[21] B. Eck, R. Dronskowski, J. Alloys Compd. 338, 136 (2002).

[22] B. Eck, Y. Kurtulus, W. Offermanns, R. Dronskowski, J. Alloys Compd. 338, 142 (2002).

[23] N.E. Brese, M. O'Keeffe, Acta Crystallogr. B47, 192 (1991).

[24] M. Yashima, S. Sasaki, M. Kakihana, Acta Crystallogr. B50, 663 (1994).

[25] H. Schilling, M. Lerch, Z. Kristallogr. Suppl. 22, 76 (2005).

[26] M. A. Taylor, M. Kilo, C. Argirusis, G. Borchardt, I. Valov, C. Korte, J. Janek, T. C. Roedel, M. Lerch, Solid State Data, Pt. A: Defect and Diffusion Forum, 237-240, 479 (2005).

[27] J. W. Adams, H. H. Nakamura, R. P. Ingel, R. W. Rice, J. Am. Ceram. Soc. 68, 228 (1985).

[28] O. Rahäuser, PhD thesis, Universität Würzburg (1998)

[29] C. Korte, J. Janek, in preparation 